\title{
Can a four-hour interactive workshop on the management of dental emergencies be effective in improving self reported levels of clinician proficiency?
}

\author{
Tony Skapetis, BDS, MEd (Adult Education) ${ }^{a, b, *}$, \\ Tania Gerzina, BDS, MDS, PhD, FRACDS, GradCertEdStud (Higher

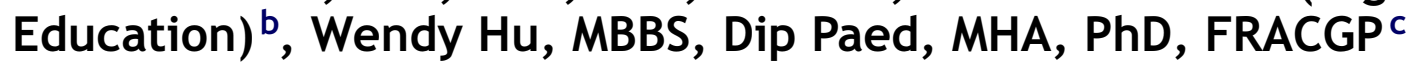

\author{
a Westmead Centre for Oral Health, Western Sydney Local Health District, Australia \\ b University of Sydney, Faculty of Dentistry, Australia \\ c University of Western Sydney, School of Medicine, Australia
}

Received 25 May 2011; received in revised form 13 December 2011; accepted 13 December 2011

\author{
KEYWORDS \\ Dental emergencies; \\ Dental education; \\ Dental workshop; \\ Primary care \\ providers; \\ Pre-post \\ questionnaire
}

\begin{abstract}
Summary
Background: Management of dental emergencies is a clinical problem facing many primary care providers who have often received little training in this area.

Aim: This study evaluated the impact of a four-hour interactive workshop on clinicians' self reported proficiency in managing common dental emergencies.

Method: A descriptive study design using a questionnaire type survey instrument was used to evaluate the effectiveness of a brief interactive workshop.

Results: The workshop positively impacted proficiency, especially in oral local anaesthesia, management of avulsed teeth and dental trauma. Open comments from participants focused on the lack of dental topics in professional training.

Recommendations: Further education is required in the management of dental emergencies such as odontogenic infections, dental local anaesthesia, trauma, intra-oral haemorrhage and in dental nomenclature.

Conclusions: An effective interactive workshop intervention employing blended instructional techniques may help improve the management of dental emergencies and patient outcomes. (c) 2011 College of Emergency Nursing Australasia Ltd. Published by Elsevier Ltd. All rights reserved.
\end{abstract}

\footnotetext{
* Corresponding author at: Westmead Centre for Oral Health, PO Box 533, Wentworthville, NSW 2145, Australia.
} E-mail address: tony_skapetis@wsahs.nsw.gov.au (T. Skapetis).

1574-6267/\$ - see front matter @ 2011 College of Emergency Nursing Australasia Ltd. Published by Elsevier Ltd. All rights reserved. doi:10.1016/j.aenj.2011.12.003 


\section{What is known}

- Dental emergencies are a common presentation to Emergency Departments and primary care practitioners. Unfortunately, clinicians are often illprepared to manage such conditions.

\section{What this paper adds}

- This paper highlights the effectiveness of an interactive workshop to address this knowledge gap.

- The article aims to heighten awareness of the need for practical high quality education, in the dental education area, as well as supply an effective template which may be used in other emergency medicine training.

\section{Introduction}

\section{Background}

Dental emergencies are not uncommon and may present to non-dental primary care providers such as physician and nursing staff in hospitals emergency departments (ED), nursing homes, consulting rooms and other care facilities. In US studies, ${ }^{1-3}$ between $1.3 \%$ and $3.8 \%$ of ED visits are due to dental complaints, and a UK study ${ }^{4}$ placed dental problems in the top three most common ED telephone complaints. Relatively simple first aid treatment for dental emergencies, which could be provided by primary care clinicians, is not only cost effective but can also improve longer term dental outcomes. ${ }^{5}$

Despite these findings, there is a continuing unmet need for dental education amongst emergency medical and nursing personnel, particularly in the area of assessment and management of dental emergencies, ${ }^{6,7}$ which is likely to apply to emergency nursing personnel as well.

Continuing health professional education (CPE) interventions targeting primary care providers, in the form of small group discussion and interactive workshops, has been reported effective in increasing knowledge and changing behaviour. ${ }^{8} \mathrm{~A}$ meta-analysis of the available evidence in fact, concluded that such strategies could benefit CPE in oral health but are often focused on oral health prevention rather than the management of acute presentations, particularly when dental service providers are not available. Whilst other studies have documented the need for dental education in medical practitioners, this is the first study on the effect of an interprofessional and multidisciplinary dental emergency educational intervention for primary care practitioners in Australia.

\section{Purpose of study}

Our study evolved from a documented need for education in the management of dental emergencies by primary care providers. ${ }^{5,9,10}$
The aim of the study was to evaluate the impact of a brief four-hour workshop on the level of clinician self reported proficiency in managing specific dental emergencies.

\section{Method}

\section{Workshop development}

The workshop was initially developed following a request for education in the management of dental emergencies from a large Australian tertiary referral hospital ED in 2005 to one of the authors (TS). Initially, the content was developed in consultation with the director of a large Emergency Dentistry Department of a university dental school, emergency medicine fellows, two directors of emergency medical training in Australia, using analysis of published literature. ${ }^{6,11}$ This literature included evidence based guidelines developed by the International Association of Dental Traumatology. ${ }^{12}$ These discussions formed the basis of the development of and educational strategy.

Between 2005 and 2007, a pilot workshop consisting of a three-hour wholly didactic presentation, was delivered to several EDs and at emergency medicine conferences. The effectiveness of these workshops was evaluated using a self assessment survey instrument. The evaluation enabled the refinement of the format and content of the workshop which was then evolved into interactive four-hour workshops delivered for this study. In addition, regular updates over several years from the dental education literature and treatment guidelines were used to inform the choice of final topics and interactive format for this workshop, to include dental nomenclature, ${ }^{13}$ local anaesthesia, ${ }^{14,15}$ trauma, ${ }^{16-21}$ haemorrhage control ${ }^{22,23}$ and odontogenic infections. ${ }^{22,24-28}$

\section{Study design and questionnaire}

The workshop was designed according to accepted principles for effective $\mathrm{CPE}^{29,30}$ and included multiple instructional techniques and multimedia modalities.

Whilst other authors have used more focused designs to evaluate the impact of dental educational interventions, ${ }^{31,32}$ this study presents a workshop with an expanded coverage across a broader range of dental emergency for a larger audience of primary care clinicians from different health professions and levels of experience. To measure the effectiveness of the workshops as an educational intervention, a pre- workshop/post-workshop questionnaire was developed to measure self-reported knowledge change and confidence in dental emergency management. Information collected in the pre-workshop questionnaire included demographics, previous dental education and training, number/type of dental emergencies treated over the previous 12 months (Fig. 1), and 10 questions measuring proficiency on key topic learning outcomes provided by the workshop using a 4 point Likert scale. The Likert scale included the possible responses; not proficient, less proficient, proficient and highly proficient.

Other CPE studies have attempted to measure changes in clinical behaviour and skills through self-assessed confidence change. ${ }^{33,34}$ Self-assessment questionnaires have 


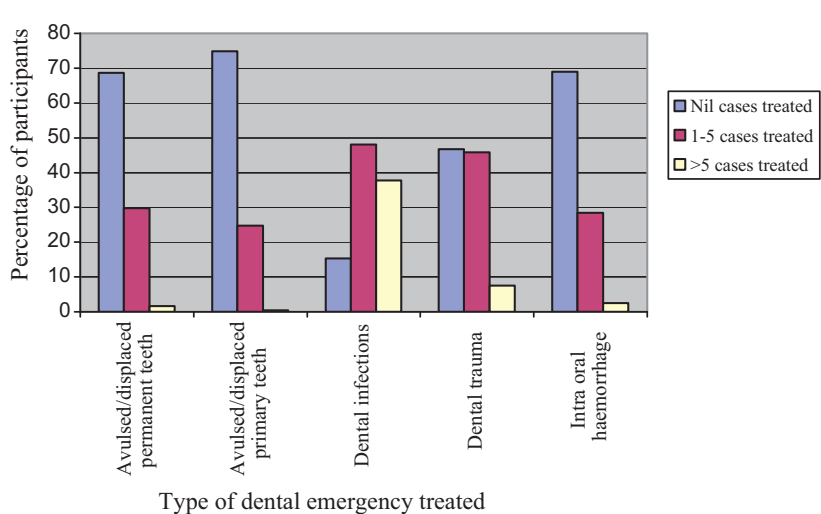

Figure 1 Participants prior experience in treating dental emergencies.

been widely used to measure performance change and several strategies are available to improve their validity. ${ }^{35}$

Items in the questionnaire were closed statements with a final question inviting open comments.

The survey instrument was validated for content and appropriate language through review by a panel of health professionals, including two dental academics, two medical academics, two emergency physicians, three general medical practitioners and one registered nurse. Minor changes were subsequently made as a result.

Discriminant validity was achieved through the use of a "dummy" question which deliberately asked respondents for their proficiency in an emergency dental care topic not covered in the workshop, namely, "management of pericoronitis". Such a "dummy" question can serve as a control for reliability of responses. ${ }^{36}$ The workshop was delivered to all participants by the same dental clinician educator using identical resources.

Both workshop and survey tool were piloted with 18 clinicians including 16 medical and two nurse practitioners. Following their responses the wording of several questions was further modified to improve construct validity.

Survey instrument reliability was tested for internal consistency amongst the similar themed Likert scale questions. This gave a Cronbach's Split Half reliability value of 0.79 for the pre-test and 0.88 for the identical post-test with a value of 0.84 overall, indicating a high internal consistency in the survey instrument.

\section{Participants and settings}

Participants were recruited through open invitation to all staff and students at 11 Australian EDs, including three metropolitan and eight regional and rural sites, and to all attendees at three rural medicine national conferences and one division of GP training conference. Participants in the study (Table 1) were medical practitioners, ED nurse practitioners and final year medical students who had elected to attend the four-hour workshop titled "Management of Dental Emergencies'. All 17 workshops were delivered between March 2009 and June 2010 by the one presenter to 242 participants. Site choice was based on invitation following advertisement of the workshop at conferences and local
Table 1 Professional background of participants.

$\left.\begin{array}{llll}\text { Professional Category } & & & \\ \text { Ungrouped } & \mathrm{n} & \text { Grouped } & \mathrm{n} \\ \text { ED specialists } & 18 & \text { ES } & 18 \\ \text { General practitioners } & 62 & \text { GP } & 62 \\ \text { Emergency registrars } & 70 & \text { ER } & 70 \\ \text { Non-emergency } & 24 \\ \text { registrars } & 26 \\ \text { Career Medical Officers } & 26 \\ \text { Nurse practitioners } & 9 \\ \text { Interns and residents } & 27 \\ \text { Medical students } & 6\end{array}\right\}$ NS 1

health networks and included three Australian states; Victoria, NSW and Queensland.

Teaching resources included slide presentations with didactic content, case studies, simulation and audiovisual (video relating to local anaesthesia techniques) material. Nissin ${ }^{\circledR}$ dental models (plastic models of teeth and jaws) were used for simulation exercises relating to the repair of crown fractures and splinting of teeth. Simulation was also used for instructing on dental local anaesthesia.

Handouts included the presentation slides as well as suggested treatment summary flowcharts relating to the management of dental trauma (Fig. 2) and dental infections (Fig. 3). The development of Fig. 2 was based on published guidelines $16-21$ and Fig. 3 was based on published reviews and was developed in consultation with an oral and maxillofacial surgeon and is a resource for General Practice Training Tasmania. ${ }^{37}$

\section{Research ethics statement}

This multi-site study was granted ethics approval from Concord Repatriation General Hospital Human Research Ethics Committee (CH62/6/2009-010). Site specific as well as relevant university human research ethics committee approvals were also obtained.

\section{Data collection}

Questionnaires were voluntarily completed immediately before and immediately after the workshop. All 242 participants completed the entire four-hour workshop. Questionnaires were numerically coded to assist in collation and analysis and preserve confidentiality. 


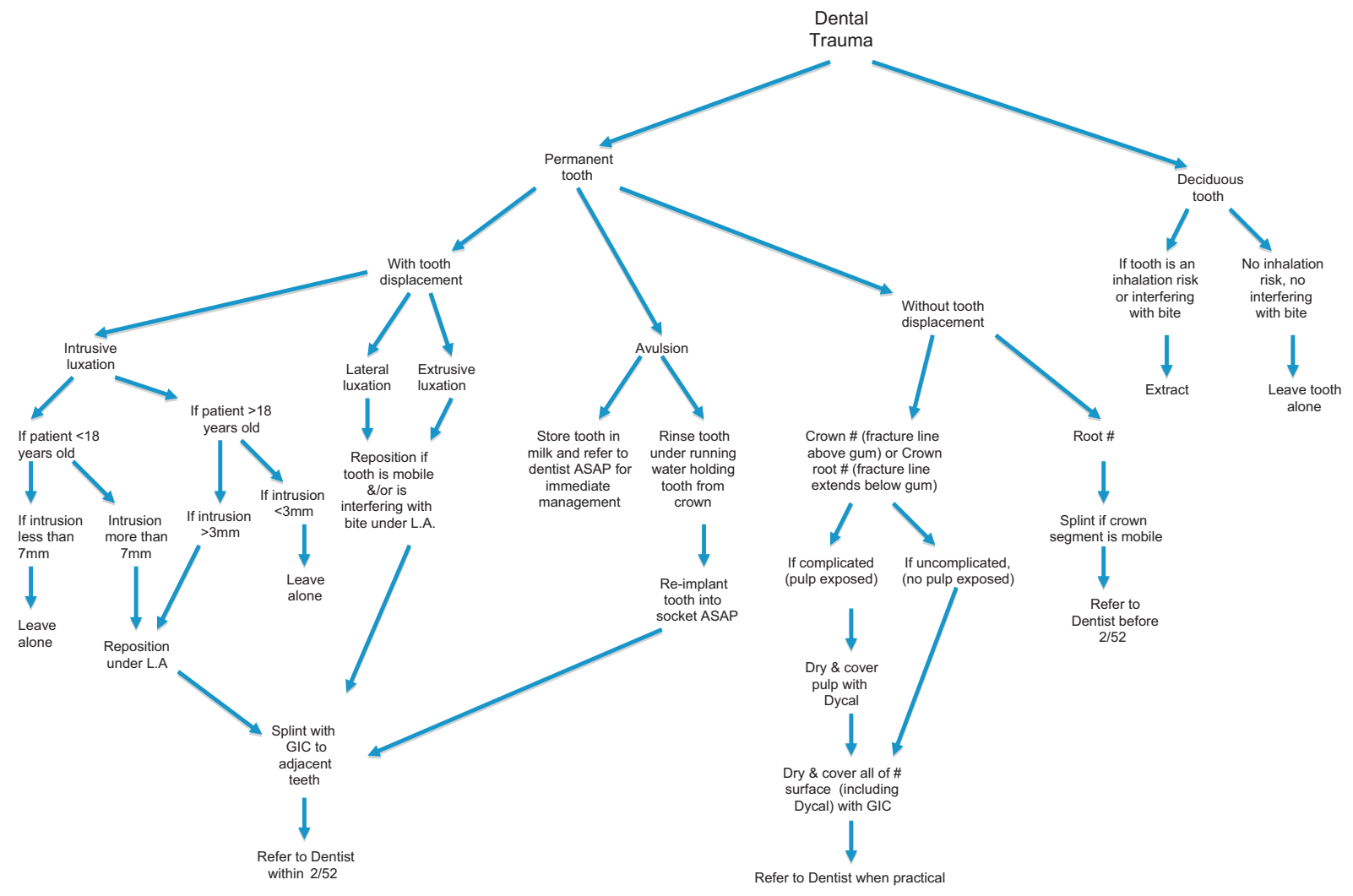

Figure 2 Dental trauma-flowchart.

\section{Data analysis}

Data was entered into SPSS version 15.0 for descriptive analysis and examined for frequency distribution. Cross tabulations were performed using Fisher's Exact Test (as several cell counts were $<5$ ) to identify associations between groups of data collected. A value of $p<0.05$ was considered statistically significant. A Wilcoxon signed rank test was performed on matched pair responses from responses to the pre and post workshop self assessment questions. The level of significance was set at $p<0.001$. Confidence intervals $(\mathrm{Cl})$ were calculated for participants who scored an improved proficiency.

\section{Results}

\section{Respondents}

Of the 242 workshop participants, all completed the full four-hour workshop and the pre and post workshop questionnaires. There was a predominance of male participants at $58.3 \%$. Most participants, $42.1 \%$, had graduated with their primary health professional degree more than 10 years previously, 31.4\% between 5 and 10 years previously and $26.5 \%$ graduated less than 5 years ago. The professional backgrounds of participants is summarised in Table 1 and for statistical analysis these professional backgrounds were grouped based on qualification and roles with respect to likely exposure to dental emergency presentations:
Emergency specialists (ES), General practitioners (GP), Emergency registrars (ER), Non-specialist hospital based generalists (including non-emergency registrars, career medical officers and nurse practitioners) (NS), Interns/residents and students (IRS).

Fifty six percent of workshop participants practised in rural locations, 35\% practised in urban locations and $9 \%$ in remote locations. There was a statistically significant association $(p<0.001)$ between professional groups and practice location with most ER $(69 \%)$ in urban practice whilst most GP (71\%), NS (68\%), ES (67\%) and IRS (58\%) in rural practice. Amongst the groups, the GP group at $26 \%$ had the highest proportion of remote practitioners, as shown in Table 2.

The relatively small number of emergency nurse practitioners $(n=9)$ relative to physicians reflects ED staffing levels reported in other literature. ${ }^{38,39}$ There were 15 emergency nurse practitioners employed by the EDs in this study not all of which are available at any one shift, representing a $60 \%$ response rate.

\section{Previous dental education or training}

$66.5 \%$ of participants reported not having received any previous dental education or training. Of the remainder that had, $19.6 \%$ had received education in the form of lectures, $13.3 \%$ from workshops, $5 \%$ from reading journals and $4.1 \%$ from Web-based resources.

Cross tabulations revealed a statistically significant association $(p<0.001)$ between years since graduation and having received previous dental education or training. With 
Dental Infections Management -- flowchart

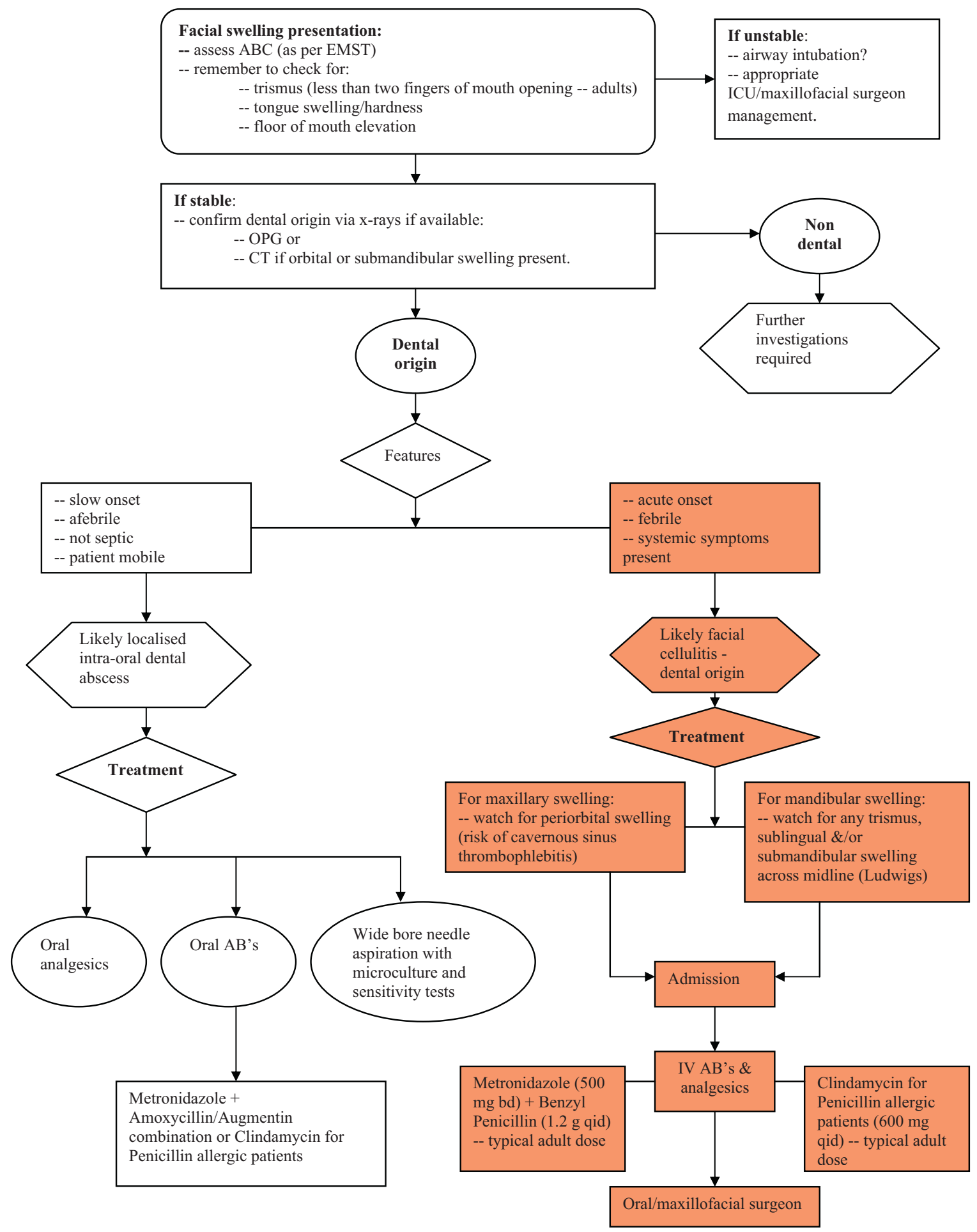

Figure 3 Dental Infections Management-flowchart.

increased years since graduation, there was an expected increased exposure to previous dental education and training. There was also a significant association $(p=0.004)$ between practice location and the types of previous dental education or training, although the strength of this association would be dependent on the length of time participants had been in rural practice and data on this was not collected. In particular, previous participation in dental workshops increased from $8.3 \%$ in urban to $38.1 \%$ for rural practice. A significant association $(p<0.001)$ was also noted between professional category and previous dental education in the form of workshops. The group 
Table 2 Practice location by professional group of participants.

\begin{tabular}{|c|c|c|c|c|}
\hline \multirow[t]{2}{*}{ Professional category grouped } & \multicolumn{3}{|c|}{ Practice location } & \multirow[t]{2}{*}{ Total } \\
\hline & Urbann & Ruraln & Remoten & \\
\hline Emergency specialist (ES) & 5 & 12 & 1 & 18 \\
\hline GP (GP) & 2 & 44 & 16 & 62 \\
\hline Intern/resident/student (IRS) & 14 & 19 & 0 & 33 \\
\hline Emergency registrar (ER) & 48 & 21 & 1 & 70 \\
\hline $\begin{array}{l}\text { Career medical officers/non } \\
\text { emergency registrars/nurse } \\
\text { practitioners (NS) }\end{array}$ & 16 & 40 & 3 & 59 \\
\hline Total & 85 & 136 & 21 & 242 \\
\hline
\end{tabular}

interns/residents and students (IRS), had not engaged in this type of training whilst $29.5 \%$ of GP, $11.1 \%$ of ES, $10.2 \%$ of NS and $8.6 \%$ of ER had previous exposure to such workshops.

\section{Types of emergency treatment provided in preceding 12 months}

92.1\% of the workshop participants had provided emergency medical services to patients.

The most commonly performed emergency dental treatment in the preceding 12 months was the treatment of dental infections, with $84.7 \%$ having treated one or more such cases and $4.1 \%$ reporting to have treated more than 30 cases. Treatment frequencies for other common dental emergencies are summarised in Fig. 1.

There was a statistically significant association $(p<0.005)$ between years since graduation and the number of occasions the participant provided treatment of avulsed/displaced permanent teeth, dental infections, dental trauma and intraoral haemorrhage. Of the participants less that 5 years post graduation, between $73 \%$ and $88 \%$ had not treated any cases of avulsion/displacement of permanent teeth, intraoral haemorrhage or dental trauma and $28 \%$ had not treated any dental infections. Over $70 \%$ of participants with more than 10 years experience had treated 1 or more cases of either dental infection or dental trauma.

\section{Pre and post-workshop self-reported proficiency}

An improvement in proficiency, self reported by participants, was recorded across the majority of management topics in the survey questions (Table 3). For example, proficiency in the ability to give dental local anaesthesia showed the largest percentage improvement and least percentage of unchanged proficiency, whilst the proficiency in management of pericoronitis showed the least improvement and largest percentage unchanged. Proficiency was further improved across the following topics; ability to provide emergency treatment for dental trauma (93.4), avulsed/displaced primary (92.2) and permanent (93.8) teeth, proficiency in describing a dental emergency (91.3) and ability to suture inside the mouth (90.1). Proficiency in appropriately managing dental infections showed high levels of unchanged proficiency (29.3).

\section{Open ended question responses}

Open comments from the pre-workshop questionnaire $(n=28)$, mostly stated that little or no training had been

Table 3 Self-reported change in proficiency following the workshop.

\begin{tabular}{|c|c|c|c|c|}
\hline & $\%$ worse & $\%$ unchanged & \% improved $(\mathrm{Cl})$ & $p$-Value \\
\hline $\begin{array}{l}\text { Proficient in describing a dental emergency to a } \\
\text { Dentist }\end{array}$ & & 8.7 & $91.3(88-95)$ & $<0.001$ \\
\hline $\begin{array}{l}\text { Able to assess the urgency of a dental emergency } \\
\text { presenting to ED }\end{array}$ & & 14.4 & $85.6(81-90)$ & $<0.001$ \\
\hline Able to give appropriate dental local anaesthesia & & 4.9 & $95.1(92-98)$ & $<0.001$ \\
\hline Able to control haemorrhage from inside the mouth & 0.8 & 12.8 & $86.4(82-90)$ & $<0.001$ \\
\hline Able to place sutures correctly inside the mouth & & 9.9 & $90.1(86-94)$ & $<0.001$ \\
\hline \multicolumn{5}{|c|}{ Can provide appropriate emergency treatment and management for } \\
\hline Avulsed or displaced permanent tooth & & 6.2 & $93.8(91-97)$ & $<0.001$ \\
\hline Avulsed or displaced primary tooth & & 7.8 & $92.2(89-96)$ & $<0.001$ \\
\hline A dental infection & 1.6 & 29.3 & $69.1(63-75)$ & $<0.001$ \\
\hline Dental trauma & 0.4 & 6.2 & $93.4(90-97)$ & $<0.001$ \\
\hline Pericoronitis $^{\mathrm{a}}$ & 9.1 & 32.7 & $58.2(52-64)$ & $<0.001$ \\
\hline
\end{tabular}

\footnotetext{
a Dummy question.
} 
received previously in this area, implying an unmet need. Post-workshop questionnaire comments $(n=103)$ were overwhelmingly positive, praising the relevancy, content and delivery of the workshop. Typical pre-workshop questionnaire comments included "utterly useless at dental emergencies" and "we need more dental training" whilst post workshop comments included "enjoyed workshop, learnt a lot, gave competence, knowledge and skills" as well as "very useful workshop, should be compulsory in med schools".

\section{Discussion}

\section{Study limitations}

This was a descriptive study of a selected, but large sample of primary care clinicians including physicians, ED nurse practitioners and medical students who had participated in a standardised brief interactive workshop on the management of dental emergencies. Whilst significant improvements in self-reported proficiency were found across a variety of clinical and non-clinical settings, the generalisability of our findings may be limited across a broader range of primary care settings and with a different dental educator. Furthermore, our findings rely on self reporting of proficiency and participants may tend to report socially desirable answers such as increased proficiency. However, the use of a "dummy" question has helped to quantify this effect, with improvements in topics that were actually delivered showing an increased improvement beyond that of the results obtained through the 'dummy' question, demonstrating that there was a net educational benefit from the workshops in improving self-assessed proficiency in the intended topics. Nevertheless, increase in self reported proficiency does not necessarily equate to increased competence in clinical settings as this complex construct remains to be reliably measured and reported. ${ }^{40}$

\section{Practice location and previous dental education and training}

The results of this study showed that previous dental education or training amongst medical personnel is minimal which supports reported findings. ${ }^{6,7,10}$

Whilst most of the participants in this study practised in rural locations, with fewer in urban and remote, this cohort is not the largest demographic group typical of the Australian medical workforce which is largely urban centric. ${ }^{41}$ This may reflect an observation that rural-located participants were more likely to take up continuing education opportunities, than both urban-located and remote-located participants.

Almost two thirds of participants had not received previous dental education or training. This compares unfavourably to international studies which show lower figures of $52 \%^{6}$ and $55 \%{ }^{11}$ and therefore much higher provision of dental training. It is likely that patient care is better served by the redress of this anomaly; this is in fact supported by participant's comments in this study.

Lectures were the predominant form of prior dental education and training amongst the study participants, followed by workshops, reading of journals and Web resources. This implies that there was little interactive or hands-on education experienced by the participants in the management of dental emergencies with lectures and other passive learning methods known to improve more theoretical knowledge, rather than practical skills.

The study shows that rural practitioners are more likely than urban practitioners to access workshops for further dental education and training. This is not surprising given that the practical skills obtained through interactive educational workshops in health professions would be relatively infrequently offered in rural and remote locations. In fact, an Australian study of nurse practitioner preferences for continuing professional development (CPD) showed that $88 \%$ of metropolitan and 94\% of rural/remote NP's preferred workshops. ${ }^{42}$ Similarly, in another study, ${ }^{43}$ rural GPs were found to prefer skill based CPD, rather than CPD that had a knowledge only focus.

\section{Experience and treatment of dental emergencies}

Less experienced clinicians, namely interns, residents and students, were more likely to have received no previous dental education or training. This may highlight an unmet education need for curriculum developers in medical schools, and anticipates recent moves towards more contemporary curriculum design, such as problem based learning and interprofessional learning, that characterise many health professional curricula. Amongst the participants, increased years after graduation was associated with increased exposure to previous dental education or training. This suggests that there may be clinician-led demand for dental education in the postgraduate years, following greater exposure to dental problems in practice.

Most of the workshop participants provided management for common dental emergencies, including dental trauma, dental infections, intra oral haemorrhage and dental pain, often associated with caries. ${ }^{44,45}$

Dental infections were the most commonly encountered presentations as they often present with severe pain. Pain has been documented as the most common complaint in patients seeking treatment outside of normal dental business hours in medical practices and ED's. ${ }^{46}$

Despite many (over 70\%) participants from all professional groups not having performed any dental local anaesthesia in the past 12 months, participants reported treating cases of dental avulsion/displacement and trauma (Fig. 1). As it is difficult to effectively treat such injuries without the use of dental local anaesthesia, it suggests that treatment may have been suboptimal, and instruction on the use of dental local anaesthesia could significantly improve management of these cases.

\section{Changes in proficiency and open ended question}

We deliberately asked respondents about proficiency rather than confidence, which implies a higher order of competence. ${ }^{47}$ As presented in Table 3, most workshop participants showed a substantial improvement in their post workshop self-reported proficiency compared to pre workshop. This improvement was greatest with respect 
to the giving of dental local anaesthesia. This change in proficiency may be attributed to the effectiveness of the workshop on this learning topic but may also be due to the fact that few participants had previously used dental local anaesthesia (28.1\%) and so participants may have been more motivated to learn this skill.

Responses to the open ended questions support the conclusion that there is an ongoing need for further health professional education in the management of dental emergencies as well a preference for the interactive workshop as a mode of educational delivery on this subject.

\section{Recommendations}

As a result of this workshop, the authors suggest:

1. Further education of primary-healthcare providers in the management of dental emergencies particularly in the area of pain management and dental anaesthesia.

2. Health care practitioners, including medical and nursing primary care providers, and in particular those based in rural settings, should receive interactive knowledge and skill based workshops for further education and training in the management of dental emergencies.

3. Any continuing professional education in dental emergencies should include the topics; dental infections, dental local anaesthesia, dental trauma, intra-oral haemorrhage and dental nomenclature.

4. For a workshop on the management of dental emergencies to be effective, it should be based on published evidence and employ multiple instructional techniques.

5. "Dummy" questions should be used more frequently to improve the rigour and validity of before and after selfreported questionnaires to evaluate the effectiveness of educational interventions.

\section{Conclusion}

Dental emergencies often present to primary care providers; treatment of dental infections is in fact the most commonly performed emergency dental procedure. Knowledge and training in assessment and management in this area is often lacking. A well designed interactive workshop format educational intervention can be effective in improving the self reported proficiency of clinicians in the management of such emergencies and in particular the ability to give appropriate dental local anaesthesia. Flowchart resources have been developed for the management of dental trauma and infections.

\section{Authors' contribution}

Tania Gerzina and Wendy Hu contributed to design, early drafts, editing and final approval of this paper.

\section{Provenance and conflict of interest}

None declared. This paper was not commissioned.

\section{Funding}

None.

\section{Acknowledgement}

Dr. Anthony Naim: Oral \& maxillofacial surgeon for his assistance in developing the Dental Infections Management flowchart.

\section{References}

1. Shortridge EF, Moore JR. Use of emergency departments for conditions related to poor oral healthcare: implications for rural and low-resource urban areas for three states. Journal of Public Health Management \& Practice 2009;15:238-45.

2. Lewis $\mathrm{C}$, Lynch $\mathrm{H}$, Johnston B. Dental complaints in emergency departments: a national perspective. Annals of Emergency Medicine 2003;42:93-9.

3. Manski R, Cohen LA, Hooper FJ. Use of hospital emergency rooms for dental care. General Dentistry 1998;46:44-7.

4. Crouch R, Patel A, Williams S, Dale S. An analysis of telephone calls to an inner-city accident and emergency department. Journal of the Royal Society of Medicine 1996;89:324-8.

5. Skapetis T, Curtis K. Emergency management of dental trauma. Australasian Emergency Nursing Journal 2010;13:30-4.

6. Patel K, Driscoll P. Dental knowledge of accident and emergency senior house officers. Emergency Medicine Journal 2002;19:539-41.

7. Skapetis T, Gerzina T, Hu W. Review article: management of dental emergencies by medical practitioners: recommendations for Australian education and training. Emergency Medicine Australasia 2011;23:142-52.

8. Sohn W, Ismail A, Tellez M, Sohn W, Ismail Al, Tellez M. Efficacy of educational interventions targeting primary care providers' practice behaviors: an overview of published systematic reviews. Journal of Public Health Dentistry 2004;64:164-72.

9. Sullivan D. Brushing up on dental emergencies. Initial care for fractures, luxations, and avulsions. JAAPA 2002;15:48-52.

10. Abu-Dawoud M, Al-Enezi B, Andersson L. Knowledge of emergency management of avulsed teeth among young physicians and dentists. Dental Traumatology 2007;23:348-55.

11. Holan G, Shmueli Y. Knowledge of physicians in hospital emergency rooms in Israel on their role in cases of avulsion of permanent incisors. International Journal of Paediatric Dentistry 2003;13:13-9.

12. Flores MT, Andreasen JO, Bakland LK. Guidelines for the evaluation and management of traumatic dental injuries. Dental Traumatology 2001:17.

13. FDI, World Dental Federation. Two-digit notation. Available from: <http://www.fdiworldental.org/two-digit-notation> [accessed 22.08.11].

14. Buckenmaier III C, Bleckner L. Anaesthetic agents for advanced regional anaesthesia: a North American perspective. Drugs 2005;65:745.

15. Malamed S. Handbook of local anaesthesia. St. Louis: Mosby; 2004.

16. Flores MT, Andersson L, Andreasen JO, Bakland LK, Malmgren $B$, Barnett F, et al. Guidelines for the management of traumatic dental injuries. I. Fractures and luxations of permanent teeth. Dental Traumatology 2007;23:66-71.

17. Flores MT, Andersson L, Andreasen JO, Bakland LK, Malmgren $B$, Barnett F, et al. Guidelines for the management of traumatic dental injuries. II. Avulsion of permanent teeth. Dental Traumatology 2007;23:130-6. 
18. Flores MT, Malmgren B, Andersson L, Andreasen JO, Bakland LK, Barnett F, et al. Guidelines for the management of traumatic dental injuries. III. Primary teeth. Dental Traumatology 2007;23:196-202.

19. University of Copenhagen. Dental trauma guide. Available from: <http://www.dentaltraumaguide.org/Permanent_Intrusion. Treatment.aspx>; 2010 [accessed 22.08.11].

20. Güngör HC, Cengiz SB, Altay N. Immediate surgical repositioning following intrusive luxation: a case report and review of the literature. Dental Traumatology 2006;22:340-4.

21. Kenny DJ, Barrett EJ, Casas MJ. Avulsions and intrusions: the controversial displacement injuries. Journal-Canadian Dental Association 2003;69:308-13.

22. Therapeutic Guidelines. Oral and dental version 1; 2007.

23. Lockhardt PB. Dental care of the medically complex patient. Elsevier; 2003.

24. Brook I, Lewis MAO, Sándor GKB, Jeffcoat M, Samaranayake L, Vera Rojas J. Clindamycin in dentistry: more than just effective prophylaxis for endocarditis? Oral Surgery, Oral Medicine, Oral Pathology, Oral Radiology, and Endodontology 2005; 100:550-8.

25. Bascones Martínez A. Consensus statement on antimicrobial treatment of odontogenic bacterial infections. Medicina Oral, Patologia Oral y Cirugia Bucal (Ed impresa) 2004: 363-76.

26. Wang J, Ahani A, Pogrel M. A five-year retrospective study of odontogenic maxillofacial infections in a large urban public hospital. International Journal of Oral and Maxillofacial Surgery 2005;34:646-9.

27. Hull MW, Chow AW. An approach to oral infections and their management. Current Infectious Disease Reports 2005;7:17-27.

28. Ellison S. The role of phenoxymethylpenicillin, amoxicillin, metronidazole and clindamycin in the management of acute dentoalveolar abscesses-a review. British Dental Journal 2009;206:357-62.

29. Alguire PC. Teaching physicians procedural skills at a national professional meeting. Medical Education 2004;9 [Online-available from professional meeting <http://wwwmed-edonlineorg>]

30. Moores LK, Dellert E, Baumann MH, Rosen MJ. Executive summary. Effectiveness of continuing medical education: American college of chest physicians evidence-based educational guidelines. Chest 2009;135:1S-4S.

31. Al-Asfour A, Andersson L, Al-Jame Q. School teachers' knowledge of tooth avulsion and dental first aid before and after receiving information about avulsed teeth and replantation. Dental Traumatology 2008;24:43-9.
32. De Lourdes Vieira Frujeri M, Costa Jr ED. Effect of a single dental health education on the management of permanent avulsed teeth by different groups of professionals. Dental Traumatology 2009;25:262-71.

33. Stewart J, O'Halloran C, Barton JR, Singleton SJ, Harrigan P, Spencer J. Clarifying the concepts of confidence and competence to produce appropriate self-evaluation measurement scales. Medical Education 2000;34:903-9.

34. Barnsley L, Lyon PM, Ralston SJ, Hibbert EJ, Cunningham I, Gordon FC, et al. Clinical skills in junior medical officers: a comparison of self-reported confidence and observed competence. Medical Education 2004;38:358-67.

35. Beckman TJ, Cook DA, Mandrekar JN. What is the validity evidence for assessments of clinical teaching? Journal of General Internal Medicine 2005;20:1159-64.

36. García EC, Otheguy RL. Being polite in Ecuador: strategy reversal under language contact. Lingua 1983;61:103-32.

37. Skapetis T, Naim A. Dental infections flowchart. General Practice Training Tasmania; 2009.

38. Lowe G. Scope of emergency nurse practitioner practice: where to beyond clinical practice guidelines? AJAN 2010;28:74.

39. Weiland TJ, Mackinlay C, Jelinek GA. Perceptions of nurse practitioners by emergency department doctors in Australia. International Journal of Emergency Medicine 2010:1-8.

40. Carslile C. Reflecting on levels of confidence and competence in skills acquisition. Medical Education 2000;34:886-7.

41. Wilkinson D, Symon B. Inequitable distribution of general practitioners in Australia: estimating need through the Robin Hood Index. Australian and New Zealand Journal of Public Health 2000;24:71-5.

42. Newman C, Buckley T, Dunn S, Cashin A. Preferences for continuing education through existing electronic access for Australian Nurse Practitioners and its implication in prescribing potential. Collegian (Royal College of Nursing, Australia) 2009;16:79-83.

43. Davies P. Continuing education for rural health workers: a medical perspective. In: 1st national rural health conference, Toowoomba. 1991.

44. Douglass AB, Douglass JM. Common dental emergencies. American Family Physician 2003;67:511-6.

45. Roberts G, Scully C, Shotts R. ABC of oral health. Dental emergencies. BMJ 2000;321:559-62.

46. Kingon A. Solving dental problems in general practice. Australian Family Physician 2009;38:211-6.

47. Gallagher AG, Ritter EM, Champion H, Higgins G, Fried MP, Moses $\mathrm{G}$, et al. Virtual reality simulation for the operating room: proficiency-based training as a paradigm shift in surgical skills training. Annals of Surgery 2005;241:364. 